\title{
O medo e a esperança: paixões humanas em Thomas Hobbes
}

\section{Antonio Marcos Conceição Liana Denise Pereira Sousa}

\section{Considerações iniciais}

$\mathrm{G}^{\mathrm{m}}$ Retórica, o termo pathos (paixão) diz respeito às provas patéticas, àquelas Eutilizadas pelo orador para obter adesão do auditório por meio do despertar dos sentimentos e das emoções. Conforme Ferreira (2010), o pathos se refere ao argumento voltado para questões psicológicas com o objetivo de afetar as emoções e sentimentos do auditório, mediante a habilidade do orador em manipulá-las em favor da adesão ao discurso que profere. Tais sentimentos e emoções, por sua vez, podem despertar amor, benevolência, medo, alegria, tristeza, esperança, repugnância, entre muitos outros. Isso requer que o orador tem de ter ciência das principais paixões que movem o auditório que objetiva persuadir. Meyer salienta que "o que Aristóteles se dispõe explicitamente a mostrar em sua Retórica é que as paixões constituem um teclado no qual o bom orador toca para convencer".

As paixões movem os homens e a forma como se dá esse fenômeno foi objeto dos escritos de Thomas Hobbes. A paixão é um dos três meios de persuasão do discurso na retórica Aristotélica. Os escritos de Hobbes estão permeados pela presença da retórica, principalmente a partir dos ensinamentos de Aristóteles e Cícero, e as paixões humanas representam a base da sua "ciência civil".

Várias são as paixões consideradas por Hobbes, mas uma delas, o medo, é que leva os homens a evitarem a guerra generalizada de todos contra todos, porém, ele não se atém apenas a essa paixão, pois os homens se habituaram às

$\overline{1 \quad \text { Meyer, 2000, p. XL }}$ 
crenças e sucumbem ao poder da eloquência. Para Hobbes, e segundo Nakayama, "a retórica é a faculdade humana que se presta a conquistar a opinião dos ouvintes". ${ }^{2}$ Ainda, o fundamento do poder dos sedutores sediciosos, e dos religiosos é a crença e a opinião do povo. ${ }^{3}$

Assim, os cidadãos são movidos pela relação de antecedência e consequência, entre o que se fala e o que se ouve. Isso é o que se encontra na relação entre o soberano e os súditos ou povo, pois os homens reagem de forma muito semelhante ao serem tocados em suas paixões que seriam as mesmas. O movimento, por Hobbes chamado "conato", tem origem na imaginação e se revela como apetite e aversão que se manifestam em dor e prazer, ou seja, pelas paixões. Dentre as paixões tratadas por aquele filósofo, abordaremos as duas principais, a saber: 0 medo e a esperança. Para melhor explanar a temática, exemplificaremos, com textos de José Simão publicados no Jornal Folha de São Paulo, aspectos importantes que fazem referência às ideias deste autor no contexto atual.

\section{Thomas Hobbes: as crenças, opiniões e o contrato social}

O homem, em todo seu percurso histórico, marcado por lutas, conquistas, manutenção de poder, dominação e subordinação, também é movido por sentimentos de esperança em um mundo harmônico. Na constante oposição entre o que deseja e o que rejeita, vive em constante luta, inclusive, e principalmente, contra o semelhante, na busca por uma vida em que a paz, a dignidade e a honra reine o mais distante possível do medo e da ameaça, real ou não, causados por fenômenos que não pode controlar.

Para se defender dos perigos reais e imaginários, a sociedade humana passou da vivência em bandos familiares para sociedades primitivas, que posteriormente evoluíram até as relações sociais atuais. Ao longo do tempo, mentes observadoras e analíticas têm contribuído para que a humanidade possa enxergar e refletir sobre os meios para a conquista da pretendida vida em harmonia. Thomas Hobbes foi um dos principais estudiosos que se debruçaram sobre o tema da vida humana em sociedade.

Hobbes, filósofo inglês, viveu no século XV na época do renascimento. Naquele tempo, o império da Inglaterra expandiu os seus domínios e conquistou os mares, mas também viveu uma guerra civil. Nesse contexto, Hobbes, que defendia a monarquia, lança Leviatã (1651). Nesse livro, o estudioso defende

\footnotetext{
2 Nakayama, 2009, p. 11

3 Ibid., p. 33
} 
a tese de que o homem age em função do próprio interesse e que para evitar a guerra de todos contra todos se faz necessária a criação de um estado forte, capaz de controlar e harmonizar a vida em sociedade por meio do estabelecimento de leis e da punição de quem as transgredir.

Isso leva a crer que o medo é a paixão que nos move. Entretanto, o medo não deve ser visto como única paixão estudada por aquele filósofo que tratou de várias outras paixões nos livros que escreveu, especialmente "Elementos da lei", e "Leviatã". Nessas obras, o autor formula a base da sua "ciência civil" em que aponta como força vital do homem a vaidade que o faz cego, e o medo que o faz enxergar. Contudo, o medo se constituiria no antídoto da ira, e não da vaidade que não guiaria todos os homens e nem os faria se matarem, porque é uma paixão comum a todos os homens. Ao contrário, a ira sim tem a capacidade de levar à guerra.

A partir das premissas da retórica hobbesiana, a ira, o medo e a vaidade são paixões importantes que se entrelaçam com outras paixões, como a esperança, a confiança, a vergonha. Todas essas paixões estão nos corações dos homens e os guiam, pois são passíveis de várias combinações dependendo do desejo e dos objetivos de quem as estimula.

As duas principais paixões que estudaremos nesse trabalho, e que estão envolvidas nesse processo são o medo e a esperança. O medo se refere à ameaça que a ausência de regras representa para o homem. Ainda mais, também se impõe o temor de que o descumprimento das normas resulte em severas sanções. Por outro lado, a esperança é a paixão que o homem creia que, em troca de uma liberdade sem restrições, o estado proporcione a segurança necessária para a sobrevivência digna dos cidadãos.

Para Aristóteles, o medo consiste numa situação aflitiva ou numa perturbação causada pela representação de um mal iminente, ruinoso ou penoso. ${ }^{4}$ Estes males, por sua vez, deveriam ser vistos como próximos de ocorrerem, pois, aqueles demasiados distantes não seriam capazes de meter medo, como é o caso da morte, que por não se apresentar como próxima não preocuparia ninguém.

Portanto, o que tememos são o ódio e o poder de quem pode nos fazer mal, pois a maior parte dos seres humanos são bastante maus. Assim, impõe-nos temor todas as coisas que inspiram compaixão e que acontecem, ou podem acontecer aos outros. Isso faz pensar que podemos vir a sofrer algum mal ou que podemos ser afetados por pessoas, coisas e momentos. Tal sentimento configura uma paixão capaz de ser utilizada 
para persuadir, pois algumas vezes é necessário despertar o temor no auditório para captar-lhe a atenção. ${ }^{5}$

A paixão contrária ao medo é a confiança, e o que inspira confiança é o contrário do que inspira medo, de forma que acreditamos que aquilo que está próximo pode nos salvar, porque a esperança concerne ao futuro.

O medo da morte, para Thomas Hobbes, é uma das paixões centrais. Segundo este filósofo, apenas a regularidade viabilizada pelo Estado soberano que confira uma constância na relação entre os homens é que pode afastar o medo de uma morte violenta e garantir a preservação da vida. Essa constância é que possibilitaria à paixão da esperança possa vigorar no convívio social e se transformar em confiança

\section{A eloquência como ferramenta de sedução}

O homem pode se surpreender com os atos que o outro pratica, uma vez que o pensamento comum é o de que as crenças, valores e visões de mundo que lhe guiam são os elementos que orientam os atos das outras pessoas. Por isso, cada um espera que as ações do outro sigam preceitos que norteiam os próprios atos. Assim, com base em opiniões e crenças, são construídos os ideais de convivência e de conformação às regras de uma sociedade. A partir desses preceitos, em uma sociedade democrática as pessoas escolhem aqueles que exercerão o poder.

Nesse sentido, as ações humanas são impulsionadas pelos mais variados motivos, mas um movimento, que o filósofo chama de "conatus", geralmente se inicia depois da elaboração de juízos de valor que são guiados pelos sentimentos de apetite, aversão, ódio, alegria e tristeza, entre outros. Dependendo da forma como são consideradas, essas paixões recebem nomes diversos, especialmente conforme a opinião que os homens têm a respeito do objeto que amam ou odeiam, e da possibilidade de obter o que almejam. Essas nomenclaturas dependem, ainda, da forma como essas paixões são consideradas em conjunto.

Ao viver em sociedade, o ser humano compartilha paixões semelhantes que diferem apenas quanto aos objetos de desejos de cada um. Esse é um dos fatores que possibilita mover os homens em coletividade. Dessa forma, mediante a eloquência é possível induzir a reforma da vontade pela conformação e condução das crenças. Segundo Hobbes, o poder de quem o exerce se fundamenta

5 Magalhães, 2012, s/p 
O medo e a esperança: paixões

na opinião e na crença do povo. Essa concepção de Hobbes se evidencia na sua afirmação de que o objetivo da retórica é obter a crença do ouvinte.

Para Hobbes, o fundamento do poder é o acordo que os homens fazem para conviver pacificamente em sociedade, mas somente a força não seria capaz de manter esse acordo, pois a obtenção e manutenção desse poder reside na eloquência. Nesse ponto, demonstra a influência de Cícero na sua teoria.

Com efeito, a respeito do poder da eloquência, Cícero, assim se manifestou:

Porém, é tamanho o poder da eloquência, que ela contém a origem, a essência, as mudanças de todas as coisas, das virotes, dos deveres, de toda a natureza, que abrange o caráter dos homens, sua vida, que ela mesma determina os costumes, as leis, as instituições, governa o estado e fala de maneira ornada e rica de tudo que diz respeito ao assunto. ${ }^{6}$

Assim, a opinião e a crença governam o mundo, e o poder exercido por um soberano se instaura por um contrato decorrente da sedução. Contudo, quando o sedutor não é o soberano, ocorre uma ruptura na sociedade e a unidade se dissolve. O sedutor move o seduzido para o lado que lhe convém, dentre eles, Hobbes cita os religiosos e os interessados na queda da monarquia.

Dessa maneira, ao compreender o que é o povo, observamos o movimento da maioria que se guia pela crença, uma vez que o apetite e o medo, como antecedentes, são as causas da nossa vontade, de acordo com Hobbes (1983). Assim, quando alguém nos propõe um ganho ou prejuízo, ou seja, uma consequência que se traduz em recompensa ou castigo, esses elementos constituem as causas da nossa vontade, e, portanto, da nossa opinião e dos nossos atos. O problema, então, é crer numa proposta e a partir dela formar a opinião.

Assim, a leitura de Thomas Hobbes nos ensina que as paixões antecedem as ações que são guiadas por crenças e opiniões. Essas, por sua vez, são despertadas pela eloquência de oradores que seduzem o povo mediante as propostas de recompensa ou castigo. Quando a maioria é seduzida pelo discurso do soberano, a sociedade se mantém coesa. Mas, quando o sedutor é alguém que a ele se opõe, advém o dissenso e o choque das crenças e opiniões que os discursos antagônicos instauram na luta pela obtenção do poder. Isso se dá porque o movimento decorrente das paixões demonstra que o povo tende a se decidir "em quem" e não, somente, "em que" acreditar.

6 Cícero apud Scatolin, 2009, p. 277 


\section{As paixões como ferramenta de manejo para adesão}

Hobbes conceitua a retórica como a arte pela qual se despertam as paixões nos ouvintes para ganhar sua crença, conforme tradução do livro Toda Arte Retórica, de Thomas Hobbes feita por Nakayama.

Retórica é aquela faculdade, através da qual entendemos o que nos servirá, acerca de qualquer tópico, para conquistar a opinião do ouvinte. Daquelas coisas que geram crença, algumas não requerem o auxílio de uma arte, como testemunhos, evidências e coisas semelhantes, que não inventamos, mas, fazemos uso, e algumas requerem arte e são inventadas por nós.

Por sua vez, Aristóteles (2005), na Retórica, mostra os três pilares fundamentais para a efetivação de um discurso eficaz, a saber: o ethos, o logos, e o pathos. O ethos diz respeito à imagem que o orador constrói sobre ele mesmo e a projeta para o auditório. De acordo com a abordagem de Ferreira: "Modernamente, o termo sofreu ampliação de sua significação e hoje se aceita como ethos a imagem que o orador constrói de si e dos outros no interior do discurso". $\mathrm{O}$ logos está voltado para a lógica, para a razão, pois conforme Aristóteles (2000), o discurso deve ser alicerçado segundo a lógica e a razão para se tornar convincente. O pathos, por sua vez, visa provocar as paixões do auditório. Embora os três sejam importantes, o estudo de cada um separadamente é relevante e aqui nos ateremos ao pathos.

Visto isso, observamos que o discurso de Hobbes (2000) está ocupado dessa prova retórica, pois ao identificar que o homem age sempre no interesse próprio ao buscar para si o que lhe é benéfico e afastar o que não lhe convém, defende que o estado, por meio do manejo das paixões (principalmente o medo e a esperança), move o povo a aceitar a submissão em troca de poder usufruir o direito de convivência pacífica em meio à pluralidade de interesses. E mais, demonstra que por conta de sua própria natureza os seres humanos seriam incapazes de manter a paz entre si.

Ao falar sobre a natureza humana, Hobbes (1983) defende que para viver em sociedade o homem estabelece um contrato social, o que está ligado às restrições linguísticas, políticas e culturais que garantem a manutenção da paz entre os diferentes grupos sociais.

$7 \quad$ Nakayama, 2009, p. 80

8 Ferreira, 2010, p. 90 
Em tal sentido, em nome da manutenção dessa paz instituída por meio do contrato social, o emprego de argumentos retóricos em defesa das restrições a expressões linguísticas e/ou ideologias que de algum modo exponham o Estado a riscos é um meio eficaz. Nesse contexto, a Retórica é instrumental para consolidar o acordo entre os interesses de cada lado, e é também por meio dela que o estado se vale de aparatos ideológicos que estimulem os indivíduos a preferirem a obediência à transgressão. Como leciona Meyer, a paixão é “(...) um estado de alma móvel, reversível, sempre suscetível de ser contrariado, invertido". Assim, a constante vigilância e controle ideológico mantém o equilíbrio sem que o poder se torne excessivamente repressivo e desperte a aversão dos súditos.

Embora as ideias de Hobbes estivessem voltadas para o regime monárquico, elas se estendem para as demais organizações políticas e para a contemporaneidade, pois é possível observar essa disputa ideológica presente na atualidade. Com efeito, nas democracias vigentes em nosso tempo, e com o advento da era da conexão, são abundantes os apelos para a desconstrução da imagem do governo e, do lado contrário, da imagem daqueles que se lhe opõem. Para ilustrar como as ferramentas retóricas podem reforçar tais ideais, apresentamos fragmentos de textos do jornalista José Simão referentes à política e ao governo atual para análise.

\section{O despertar das paixões como estratégia para a desconstrução do discurso}

As percepções do homem a respeito de situações e eventos no mundo são influenciadas pelo despertar das emoções, das paixões, de forma que os propósitos do orador no sentido de persuadir e exercer influência sobre o outro são medidos de acordo com os desejos e intenções. Assim, o quanto o orador teve êxito em agregar ou desagregar, estabelecer acordos e difundir oposições pode ser desvendado mediante análise dos elementos retóricos que norteiam o discurso proferido.

Para compreendermos as implicações práticas dos ensinamentos de Hobbes e a forma como eles se materializam nos discursos, escolhemos para corpus e análise algumas passagens de discursos de políticos brasileiros e trechos dos textos de José Simão, jornalista que se notabilizou pelas sátiras que apresenta nas colunas jornalísticas que escreve a respeito dos fatos cotidianos.

$9 \quad$ Meyer, 2000, p. XXXIX 
O emprego de figuras de estilo foi bem analisado por Meyer (2018) ao mencionar que o assunto que é matéria de debate entre os homens pode ser apresentado de forma direta e literal, mas dessa forma só há o desacordo ou a adesão pura e simples. Entretanto, a expressão pode ser usada de forma sutil, indireta, também chamada tropológica. "Um tropo, ou figura de estilo, é um desvio de sentido, um rodeiro inabitual relativamente ao sentido literal". ${ }^{10}$

O presidente Jair Bolsonaro afirmou nesta quarta-feira, 27, que não houve ditadura militar no Brasil, mas admitiu que houve "probleminhas" no regime que iniciou em 1964 e foi até 1985. "Não quer dizer que foi uma maravilha. Não foi uma maravilha regime nenhum. Qual casamento é uma maravilha? De vez em quando tem um probleminha, é coisa rara um casal não ter um problema", comparou o presidente em entrevista à TV Bandeirantes, após ser intimado por uma juíza de Brasília a se manifestar sobre 'festejo' de 31 de março. ${ }^{11}$

Conforme podemos perceber no contexto retórico referente à comemoração referente ao regime militar, celebrada em 31 de março de 2019, ao ser questionado em entrevista, o presidente do Brasil, Jair Bolsonaro, afirmou que no Brasil não houve ditadura militar, mas apenas uns probleminhas.

Bolsonaro diz que não houve ditadura, mas "uns probleminhas". Probleminhas: pau de arara, choque elétrico e um primo preso carregando o livro $\mathrm{O}$ Vermelho e o Negro! ${ }^{12}$

Notamos nas frases estudadas que uma das estratégias retóricas de José Simão é justamente apontar os contrastes presentes no discurso político do atual Presidente brasileiro. Com efeito, isso se dá de duas formas, a primeira ao aproximar ações/discurso e, outras vezes, ao usar figuras de estilo.

Vemos que o humorista propositalmente emprega a figura da ironia para remeter ao oposto do sentido empregado pelo presidente brasileiro. A expressão que utiliza vai além da simples comicidade e chega a ser sarcástico diante da gravidade dos fatos ocorridos naquele período aos quais ele se expressa literalmente.

Por meio de textos de natureza opinativa, percebemos que José Simão articula argumentos, provoca leitores, questiona e especialmente, constrói referências humorísticas que problematiza os diversos discursos que circulam na sociedade e que estão em evidência. Trata-se de uma metalinguagem às avessas em que a palavra ressignifica a própria palavra.

10 Id., 1998, p. 105

11 https://istoe.com.br/comemoracao-de-1964-ficara-dentro-dos-quarteis-diz-bolsonaro-em-entrevista-na-tv/

12 José Simão, https://twitter.com/jose_simao/status/1111395231331696642 
Essa estratégia explora o humor e demonstra um posicionamento argumentativo sobre ideologias, o que remete, novamente a questões propostas pela retórica, como podemos observar na manifestação que aquele humorista faz a respeito da afirmação de Jair Bolsonaro ao comemorar o período de regime militar no Brasil, no mês de março de 2019:

Assim, a partir dos discursos de Jair Bolsonaro, atual presidente brasileiro, José Simão elabora referências humorísticas que o ridicularizam. Para tanto, emprega cacofonias e ambiguidades, mas evita os eufemismos recorrentes em discursos em que a estratégia retórica é não transgredir os tabus linguísticos.

Ao afirmar que uma determinada ideologia é soberana em detrimento de outra por proteger os interesses do Estado, em especial, ao garantir o bem-estar social, é possível entender que todos os indivíduos devem respeitar leis, dogmas e restrições em favor de um bem-estar maior que se refere à coletividade, fundamento básico do contrato social.

No contexto da disputa entre os interesses econômicos de alguns, e as questões de preservação ambiental defendida por várias organizações como sendo de interesse geral da coletividade, assim se manifestou o atual mandatário brasileiro:

O Brasil é uma potência no agronegócio. A Europa é uma seita ambiental, não preservaram nada e atiram em cima de nós o tempo todo de forma injusta, é uma briga comercial. Há interesse em todo o Brasil, somos bombardeados 24 horas por dia. Parte da mídia aproveita o momento para criticar o governo, como se anteriores estivesse uma maravilha a questão ambiental no Brasil. ${ }^{13}$

José Simão, na qualidade de orador, problematiza tais argumentos. Para tanto, utiliza o discurso político atual para provocar o auditório a ver certos fatos a partir de outra perspectiva, como é o caso da frase: "Pantanal! Fogo acima de tudo! Fumaça Encima de Todos!" ${ }^{14}$ Dessa forma, associa a tragédia ecológica, econômica e social que assola o país ao próprio governo, e vincula a situação devastadora ao lema que o simboliza.

Na segunda parte do livro The art of rhetoric plainly set forth with pertinent example, Thomas Hobbes ensina a mover os homens pelas paixões, ao afirmar que "As paixões que inclinam os homens à paz são: medo da morte; desejo

13 https://noticias.uol.com.br/meio-ambiente/ultimas-noticias/redacao/2020/07/16/bolsonaro-ve-criticas -injustas-por-desmatamento-e-uma-briga-comercial.htm

14 José Simão, https://twitter.com/jose_simao/status/1306643915840389121 
de coisas tais que são necessárias para uma vida cômoda e uma esperança de obtê-las por sua própria indústria." ${ }^{15}$

Ainda nesse sentido, ao narrar episódios da guerra civil inglesa, Hobbes mostra como o poder era fundamentado pela crença, em virtude da qual decorre a opinião. O presidente Bolsonaro, como soberano orador na atualidade sempre procura reverter notícias que lhe são desfavoráveis ao imputar as causas pelos erros imputados aos seu governo àqueles que se opõem ao seu governo. Como exemplo dessa tendência apontamos o caso da falha nas notas do ENEM (exame nacional do ensino médio) de 2019, fato largamente noticiado, sobre o qual o mandatário brasileiro diz que vai conversar com o então ministro da educação, Weintraub, pois "se realmente foi uma falha nossa, se tem uma falha humana, sabotagem..." Em contrapartida, José Simão se manifesta da seguinte forma:

"Bolsonaro diz que situação do Enem pode ser sabotagem." Pelo próprio ENEMGÚRMENO que ele nomeou como ministro. Que não sabe nem escrever! Piauí Herald: "Governo tenta criar Secretaria da Sabotagem, mas foi interrompido por uma possível sabotagem". Sabotaram a sabotagem! Rarará! Tudo no Brasil é sabotagem. Vídeo nazista: sabotagem de Satã. Amazônia: sabotagem do DiCaprio. Água da Cedae: sabotagem da Geominas. Como escreveu o Weintraub, IMPRECIONANTE ÇABOTAGEM! Rarará! Sisu vira Sifú! E MEC: Ministério dos Estudantes Cagados! ${ }^{16}$

Novamente a figura da ironia, tanto na forma explícita, como implícita, ressalta as incongruências das escolhas feitas pelo governo. Nesse sentido, ao se referir ao então ministro da educação cria o termo "enemgúrmeno", além das alterações promovidas nas palavras que resultaram nos vocábulos "impressionante" e "çabotagem" para identificar por meio dos sentidos explícitos como a o ministro da educação que ele nomeou não sabe nem escrever, ou implícitos, como ENEMGÚRMENO, IMPRECIONANTE, e, ÇABOTAGEM, que remete à contradição da nomeação do ministro justamente para a área da educação.

Assim, avaliam-se e julgam-se discursos, expressões e ideologias à margem dos interesses desses discursos institucionalizados por meio desse contrato social mediante o qual o povo se sujeita a um soberano em razão do medo da morte e de sofrimento de outros males. Em tal sentido, o orador ao usar determinadas expressões e/ou defender determinados posicionamentos que despertem a paixão

15 Hobbes (Lev, 1952, I, XIII, p. 86) apud Nakayama, 2009, p. 26, tradução nossa

16 https://www1.folha.uol.com.br/colunas/josesimao/2020/02/enem-weintraub-e-cabotagem.shtml 
correspondente, seja para avivar o medo, ou reacender a esperança, obtém e a opinião favorável às suas teses. Por sua vez, o homem se sente inserido nesse pacto social, ou dele excluído, caso não seja atendido nos seus desejos, ou the seja proposto o que tem aversão. Esse sentimento de pertencimento e esse medo de exclusão, por vezes, dita comportamentos e mantém o controle do estado em harmonia com o povo.

Conscientes dessas nuances, mesmo que de forma empírica, os políticos seduzem pelo discurso e movem o povo para a direção que melhor atenda aos seus interesses de poder. Por outro lado, aqueles que lhes criticam também usam as paixões para mover o povo no sentido oposto, de forma que os argumentos de um ou outro lado tendem a despertar mais as paixões no auditório do que a razão.

Por certo, em virtude do medo, o homem vive tutelado por uma sociedade que, em contrapartida, direta ou indiretamente, exige dele a manutenção dos contratos sociais. Assim, conforme Hobbes (1983), o Estado restringe a liberdade do homem, mas o protege dele mesmo, um ser naturalmente mau. Em complemento, ainda o protege da maldade dos outros homens. Logo, o medo da falta ou da perda desses bens, é retoricamente defendido e mantido pelos homens arrebanhados por essa lógica contratual que impõe a cessão de parte da liberdade em favor de segurança. Essa condição faz com que os contratos sociais sejam mantidos ou reformulados de acordo com os interesses dos integrantes de uma determinada sociedade.

O humor satírico é o principal instrumento argumentativo de José Simão para questionar o discurso político vigente, como vemos no comentário elaborado logo depois da divulgação de um vídeo da ministra Damares Alves com a afirmação de que menino veste azul e menina veste rosa. A esse respeito diz José Simão: "Corre na internet a biblioteca da Damares: 'Guimarães Rosa para meninas, Guimarães Azul para meninos e sem Eça de Queiroz!'. Rarará!”. ${ }^{17}$

Nesse trocadilho, José Simão novamente questiona os ideais extremamente conservadores que a frase evoca, pois de forma implícita o sentido é de condenação à diversidade de gênero. Logo, por meio de um jogo linguístico, expõe o jogo político que circula tanto no campo das palavras quanto das ideias. Ao escrever “Eça de Queiroz!", faz uma crítica ao contexto das acusações contra Fabrício Queiroz e o possível envolvimento de pessoas ligadas ao governo em atos supostamente criminosos.

Investigamos, também, outra paixão mencionada por Hobbes (1983), a esperança, que está intimamente ligada à manutenção harmônica dos acordos

17 José Simão, https://www1.folha.uol.com.br/colunas/josesimao/2020/01/ueba-a-noivinha-do-bolsonaro.shtml 
entre o governo com os que a ele se aliam, e o povo, por meio da retórica. Em seus discursos, os políticos contemporâneos apresentam as vantagens de um contrato social ao prometer bem-estar social, segurança, empregos, e associar tais promessas à fé, religião e/ou religiosidade.

Assim, buscam a eficácia discursiva no sentido de mover os eleitores e desenvolver uma opinião favorável e a crença de melhoria nas suas condições de vida. Por meio desse novo contrato, oferecem aos eleitores o atendimento às necessidades em troca de votos. E no contexto atual, é perceptível o uso estratégico da retórica para conquistar e manter constantemente a adesão dos "súditos", nesse sentido, podemos observar nas promessas de acabar com a audiência de custódia, bem como as saídas temporárias, e de redução da maioridade penal que foram feitas pelo presidente Bolsonaro durante a sua campanha eleitoral.

Percebemos que no Brasil, de 2018 aos dias atuais, o discurso de Hobbes (1983) acerca da imposição de limites e das regras em favor da segurança pública se faz presente. Esse controle estabelecido por meio da restrição de particularidades, em prol de um conjunto de valores sociais, justifica a delegação da segurança ao Estado. Vemos que, por meio da manipulação do medo e da esperança que é despertada no povo pelo orador, consolida-se a crença de que o orador, caso eleito, defenderá as leis, limitará os direitos dos que tenham condutas desviantes, e lhes imporá castigos. Essas promessas, então, soam como a contrapartida da segurança oferecida por governos pela sujeição do povo aos comandos de quem exerce o poder.

Em virtude dessa relação entre o modelo hobbesiano e a modernidade, na realidade brasileira e no contexto político atual, discutimos as paixões humanas, o medo e a esperança. Logo, observamos que alguns grupos defendem esse modelo restritivo de vida, além de restringir os ideais libertários em prol da garantia de segurança que nem sempre atende à pluralidade presente no âmbito social. Contudo, outros grupos se opõem a esse discurso que, por vezes, beira a exclusão e o ódio. Com fundamentos contrários, questionam e buscam desconstruir alguns conceitos conservadores que circulam socialmente.

Avaliamos em tal contexto, que o texto de José Simão problematiza os posicionamentos do atual governo brasileiro e a parcela significativa da população que o apoia. Com efeito, o eleitor elegeu tais pressupostos ideológicos em troca de segurança, como enfrentamento ao medo. Assim, foi seduzida pelo discurso que prometia o fim da corrupção, o retorno das práticas morais conservadoras, e assim restaurou no auditório a esperança.

Em José Simão, observamos o questionamento e a problematização do discurso repressivo do governo, ao qual se atribui a finalidade de doutrinação ideológica da população. Por outro lado, um número expressivo de pessoas se identifica com a construção de um ethos popular que se amolda aos anseios 
O medo e a esperança: paixões

desses indivíduos. Ciente dessa condição, o presidente propaga valores morais e ideológicos que são instrumentos de manutenção dos acordos sociais que propõe.

Ao dizer: "No Carnaval é proibido pensar!", o jornalista, ironicamente, questiona a respeito da vigilância que o governo faz acerca dos discursos que lhe são opostos. Logo, segundo José Simão, para dar manutenção à promessa de segurança há um custo: "não questione os nossos atos".

Faz-se necessário dizer que José Simão recupera mais um elemento hobbesiano: a esfera punitiva prevista pelo controle, extremamente relevante ao governo vigente, pois em Hobbes (1983) se destaca a necessidade humana de punir e castigar o outro, o que de outra forma também foi abordado por Foucault:

\begin{abstract}
Punidas pelo castigo que se atribui a função de tornar o criminoso "não só desejoso, mas também capaz de viver respeitando a lei e de suprir às suas próprias necessidades"; são punidas pela economia interna de uma pena que, embora sancione o crime, pode modificar-se (abreviando-se ou, se for o caso, prolongando-se), conforme se transformar o comportamento do condenado; são punidas, ainda, pela aplicação dessas "medidas de segurança" que acompanham a pena (proibição de permanência, liberdade vigiada, tutela penal, tratamento médico obrigatório) e não se destinam a sancionar a infração, mas a controlar o indivíduo, a neutralizar sua periculosidade, a modificar suas disposições criminosas, a cessar somente após obtenção de tais modificações. ${ }^{18}$
\end{abstract}

Assim, o ideal moral de castigo e controle como o argumento é defendido pelo governo para garantir a segurança, e ao mesmo tempo controlar a liberdade da população, especialmente diante da incapacidade do povo de observar as regras, e manter o autocontrole, o que justifica o aumento da repressão. Essa condição é questionada por José Simão da seguinte forma: "Chargista Duke batizou a campanha de abstinência sexual da Doidamares de Foda Zero! Rarará! E tem que transar antes do casamento, sim, porque depois do casamento não transa mais". ${ }^{19}$

Nessa passagem, o colunista se refere à defesa que a ministra Damares Alves faz do retardamento do início da vida sexual dos adolescentes em prol da proteção do amadurecimento do indivíduo em todos os âmbitos, inclusive no que se refere a relacionamentos afetivos. Ao citar o chargista Duke, Simão comunga da ideia de que, na sociedade atual, essa discussão pode não caber mais, uma

18 Foucault, 1999, p. 22

19 José Simão, https://www1.folha.uol.com.br/colunas/josesimao/2020/02/enem-weintraub-e-cabotagem.shtml 
vez que no contexto atual o sexo não é mais visto de forma conservadora pela maioria dos indivíduos, como outrora. Dessa forma, a frase em análise instiga o leitor a ver tal proposta como inadequada.

Portanto, observamos discursos políticos do presidente da república Jair Bolsonaro e seus apoiadores, o emprego da sedução por meio do despertar das paixões como forma de mover o auditório por meio do apelo às suas crenças, e assim obter a opinião que lhes é favorável como forma de manter o poder e angariar o apoio às suas ações.

Em síntese, concluímos que por meio da exploração de figuras de sentido, notadamente a ironia, José Simão critica os posicionamentos conservadores dos atuais detentores do poder político na esfera federal brasileira. Dessa forma, busca a adesão daqueles que têm uma opinião oscilante em relação ao presidente Bolsonaro, bem como consolidar a opinião daqueles que a ele se opõem.

\section{Considerações finais}

Neste capítulo pretendemos mostrar um novo ponto de vista a respeito das ideias de Hobbes, especialmente quanto aos autores que entendem ter o filósofo inglês se afastado da retórica, como é o caso principalmente de Skinner, conforme menciona Nakayama (2009) 20: "Skinner sustenta que, a partir de 1630, Hobbes abandona os estudos das humanidades em favor da ciência, negando e derrubando os alicerces da arte retórica”. Para sustentar essa afirmação, cita a seguinte passagem:

É nos Elementos, no entanto, e mais ainda em Sobre o Cidadão que Hobbes deixa perfeitamente claro o seu desapreço e a sua desconfiança em relação às artes retóricas e, de um modo geral, à cultura retórica do humanismo renascentista. Não seria exagero dizer que um de seus principais objetivos, nesses dois livros, é questionar e derrubar os esteios centrais da ars rhetorica. ${ }^{21}$

Os autores referenciados, especialmente Nakayama que traduziu a obra The art of rhetoric plainly set forth with pertinent examples, utilizada como corpus de análise de sua dissertação de mestrado, mostram nova perspectiva de análise da 
obra de Hobbes, que integra uma visão a partir de outra perspectiva a respeito de como aquele autor pensava a retórica, especialmente quanto às paixões.

Vimos que o autor conceituava a retórica como "a faculdade humana que se presta a conquistar a opinião do ouvinte", e, ainda, uma "arte de bem falar"22 que se subdividia em elocutio e pronuntiatio. ${ }^{23}$ Assim, seguiu os ensinamentos de Aristóteles, Isócrates, Cícero e Quintiliano.

Segundo Hobbes, as paixões humanas necessariamente não são perversas em si mesmas (prefácio do livro Cidadão), e nem os desejos e outras paixões são um pecado e nem mesmo as ações que delas derivam. Nesse sentido, todo o movimento humano é precedido pelo despertar das paixões.

Diante disso, o homem, guiado pela necessidade de sobrevivência, e ante o medo de perder a vida, os bens, o status na sociedade em que vive, renuncia a parte da liberdade em prol da vida em comunidade. Essas paixões podem ser provocadas pela eloquência dos oradores que, de forma sedutora, o conduzem na direção pretendida.

Com efeito, os discursos visam a provocar as paixões no auditório sobre as vantagens ou desvantagens de seguir determinada orientação, seja em favor do povo ou do próprio orador que o profere. Esse, por sua vez, pode ser um político que detém o poder ou da oposição, e ainda, os críticos que integram a sociedade, como é o caso do autor estudado, o jornalista José Simão.

Concluímos, pela leitura de Thomas Hobbes, bem como pelos discursos analisados, que ao lado da espada, a eloquência mantém o acordo social, e o homem, parte fundamental de um estado se guia pelas paixões, pelas crenças e por opiniões. Essas, por sua vez, são despertadas pela eloquência de oradores que seduzem o povo mediante as propostas de recompensa ou castigo, com objetivos de obter ou manter o poder. Portanto, o movimento decorrente das paixões demonstra que o povo tende a se decidir em "quem", e não somente em "que" acreditar.

22 Hobbes (Rhet I, I, I) apud Nakayama, 2009, p. 424

23 Ibid, p. 513 


\section{Referências}

ARISTÓTELES. A Retórica das paixões. São Paulo: Martins Fontes, 2000.

Retórica. Prefácio e introdução de Manuel Alexandre Júnior Tradução e notas de Manuel Alexandre Júnior, Paulo Farmhouse Alberto e Abel do Nascimento Pena. Centro De Filosofia da Universidade de Lisboa. Lisboa: Imprensa Nacional-Casa da Moeda, 2005.

FERREIRA, L. A. Leitura e persuasão: Princípios da análise retórica. São Paulo: Contexto, 2010.

FOUCAULT, M. Vigiar e punir: nascimento da prisão. Trad. de Raquel Ramalhete. Petrópolis, Vozes, 1987. 288p.

HOBBES, T. De Cive ou les fondements de la politique (tradução de S. Sorbière), Paris: Éditions Sirey, 1981.

. De Homine e De Cive, editado por B. Gert com o título Man and Citizen, Cambridge: Haackett Publishing Company, 1991.

. De la Nature Humaine, traduzido do inglês para o francês pelo barão d'Hilbach, comentário de E. Roux, Saint-Amand-Montrond: Actes Sud, 1997.

. Do Cidadão, tradução de Renato Janine Ribeiro. São Paulo: Martins Fontes, 1993.

. Leviatã ou matéria, forma e poder de um Estado eclesiástico e civil. $3^{\mathrm{a}}$ ed. São Paulo: Abril Cultural 1983.

. Natureza Humana (primeira parte dos Elementos da Lei), editado pela Imprensa Nacional - Casa da Moeda, Lisboa 1983.

MEYER, M. Aristóteles ou a retórica das paixões. In: ARISTÓTELES. Retórica das paixões. Trad. Isis Borges da Fonseca. São Paulo: Martins Fontes, 2000. p. XVII-LI.

Questões de retórica: linguagem, razão e sedução. Lisboa: Edições 70, 2018.

NAKAYAMA, P. A Arte Retórica de Thomas Hobbes - tradução e comentário. 2009. f. Dissertação (mestrado). Faculdade de Filosofia, Letras e Ciências Humanas, Universidade de São Paulo, 2009.

SCATOLIN. A invenção no Do orador de Cícero: um estudo à luz de Ad familiares I. 9, 23. Tese (doutorado) Faculdade de Filosofia, Letras e Ciências Humanas, Universidade de São Paulo, 2009. 